\title{
Research
}

Tau-Hong Lee, Joshua GX Wong, David CB Lye, Mark IC Chen, Victor WK Loh, Yee-Sin Leo,

Linda K Lee and Angela LP Chow

\section{Medical and psychosocial factors associated with antibiotic prescribing in primary care:}

\author{
survey questionnaire and factor analysis
}

\begin{abstract}
\section{Background}

Acute upper respiratory infections (AURI) are the leading causes of antibiotic prescribing in primary care although antibiotics are often not indicated

\section{Aim}

To gain an understanding of the knowledge attitudes, and practices (KAP) of GPs in Singapore and the associated latent factors to guide the implementation of an effective programme to reduce antibiotic use in primary care.
\end{abstract}

\section{Design and setting}

An anonymous survey on the KAP of antibiotic use in AURI of GPs in Singapore.

\section{Method}

KAP survey questionnaires were posted to all GPs from a database. To ascertain the latent factors affecting prescribing patterns, exploratory factor analysis was performed.

\section{Results}

Among 427 responses, 351 (82.2\%) were from

GPs working in private practice. It was found that $58.4 \%$ of GPs in the private versus $72.4 \%$ of those in the public sector recognised that $>80 \%$ of AURIs were caused by viruses ( $P=0.02$ ). The majority of GPs (353/427; 82.7\%) felt that antibiotics were overprescribed in primary care. Significant factors associated with low antibiotic prescribing were good medical knowledge and clinical competency ladjusted odds ratio [aOR] $3.2 .95 \%$ confidence interval $[\mathrm{Cl}]=2.4$ to $4.3 \mathrm{l}$, good clinical practice laOR $2.7[95 \% \mathrm{Cl}=2.0$ to 3.6]), availability of diagnostic tests (aOR 1.4 [95\% $\mathrm{Cl}=1.1$ to 1.8$]$, and desire to improve clinical practice laOR $1.5[95 \% \mathrm{Cl}=1.2$ to 1.9$]$ ]) The conservative practice of giving antibiotics 'to be on the safe side' is significantly less likely to be associated with low antibiotic prescribing laOR $0.7[95 \% \mathrm{Cl}=0.5$ to 0.9$]$ ).

\section{Conclusion}

This is the first KAP survey on antibiotic prescribing for AURI among GPs in Singapore. With the latent factors identified, future interventions should be directed at addressing these factors to reduce inappropriate antibiotic prescribing

\section{Keywords}

acute upper respiratory infections; antibiotics; knowledge, attitudes and practices; factors: primary care.

\section{INTRODUCTION}

Acute upper respiratory infections (AURI) are leading causes of attendance in general practice. Despite the fact that the majority of AURI are caused by viruses and that antibiotics are not recommended for the common cold, acute rhinitis, ${ }^{1}$ and acute bronchitis, ${ }^{2}$ antibiotics continue to be overprescribed in these settings. ${ }^{3,4}$ Acute respiratory syndromes account for approximately $75 \%$ of ambulatory antibiotic prescription in the US. ${ }^{5}$ In the UK, the use of antibiotics in general practice, accounting for $74 \%$ of antibiotics use overall, increased by $6.4 \%$ from 2010 to $2014 .{ }^{6}$ Inappropriate antibiotic use exposes patients to unnecessary drug toxicities, drug-drug interactions, increased healthcare costs, and risk of infections by communityacquired drug-resistant organisms. ${ }^{7-10}$ In Singapore, AURI accounted for $30 \%$ of all primary care consultations. ${ }^{11}$ Antibiotics were among the top 10 drugs prescribed in primary care polyclinics in the public sector. $^{12}$ In just a decade lfrom 1997 to 2007-2008), the prevalence of multidrugresistant Streptococcus pneumoniae in Singapore jumped from $33.3 \%$ to $74.6 \%{ }^{8}$

T-H Lee, MRCP, FAMS, infectious diseases physician; JGX Wong, BCom, medical statistician: LK Lee, MPH, assistant manager, Communicable Disease Centre, Institute of Infectious Diseases and Epidemiology, Tan Tock Seng Hospital, Singapore. DCB Lye, FRACP, FAMS, infectious diseases physician, Communicable Disease Centre, Institute of Infectious Diseases and Epidemiology, Tan Tock Seng Hospital; Yong Loo Lin School of Medicine, Singapore. MIC Chen, MBBS, MMed, MSc, assistant professor ALP Chow, MBBS, MMed, MS, FAMS, Grad Dip, clinical epidemiologist, Saw Swee Hock School of Public Health, National University of Singapore; Communicable Disease Centre, Institute of Infectious Diseases and Epidemiology, Tan Tock Seng Hospital, Singapore. VWK Loh MBBS, MMed, family physician, Division of Family Medicine, Department of Medicine, University Medicine Cluster, National University Hospita System, Singapore. Y-S Leo, MMed, MPH,
The decision to prescribe antibiotics to a patient with AURI is complex and many factors are involved. These include:

- physicians' fears of patients having medical complications: ${ }^{13}$

- insufficient physician knowledge; $;^{14}$

- belief that antibiotic resistance was not a problem at the community level: ${ }^{15}$

- underestimating the effect that inappropriate prescribing of antibiotics has on microbial resistance; and ${ }^{16}$

- perceived patient expectation of an antibiotic. $^{17,18}$

The above reasons influencing antibiotic prescribing can be partly accounted for by socioeconomic and cultural environments, which differ between geographical locations and communities. ${ }^{19,20}$

The World Health Organization (WHO) in its Global Action Plan on Antimicrobial Resistance ${ }^{21}$ has identified optimising antimicrobial medicines as one of its strategic objectives. To guide the design and implementation of strategies to reduce antibiotic use for AURI in Singapore, the
FRCP. FAMS, infectious diseases physician Communicable Disease Centre, Institute of Infectious Diseases and Epidemiology, Tan Tock Seng Hospital; Saw Swee Hock School of Public Health, National University of Singapore, Singapore.

\section{Address for correspondence}

Tau-Hong Lee, Tan Tock Seng Hospital, Institute of Infectious Diseases and Epidemiology, Communicable Disease Centre, 11 Jalan Tan Tock Seng, Singapore, 308433, Singapore.

E-mail: tau hong_leedttsh.com.sg

Submitted: 16 June 2016; Editor's response: 28 August 2016; final acceptance: 30 September 2016.

CBritish Journal of General Practice

This is the full-length article (published online 17 Jan 2017) of an abridged version published in print. Cite this version as: Br J Gen Pract 2017; DOI: https://doi.org/10.3399/bjgp17X688885 


\section{How this fits in}

It is known that antibiotics are overprescribed in primary care and drug resistance is one of the most pressing issues today. So far there have been no studies in Singapore examining the factors affecting antibiotic prescribing for acute upper respiratory infections (AURI) among primary care physicians. This study found that good medical knowledge and clinical practice, together with availability of diagnostic tools and GPs' desire to improve clinical practice, are important factors in reducing antibiotic prescribing. These findings will help guide future studies and interventions on antimicrobial stewardship in the primary care setting.

authors conducted a survey of GPs to ascertain their knowledge, attitudes, and practices (KAP) in antibiotic prescribing for AURI in Singapore. The authors believe that this is the initial step for reducing antibiotic use in primary care.

\section{METHOD}

\section{Survey questionnaire}

After reviewing the related literature, a survey instrument was developed (Appendix 1) with questions on the KAP of primary care physicians towards antibiotics prescribing for AURI in Singapore. It was tested for practicality and ease of use on 10 junior doctors working in a medical department, feedback was collected, and adjustments then made. Questions were either on a 4-point $\quad(1=$ never, $\quad 2$ = infrequently, 3 =frequently, 4 =always) or a 5-point Likert scale lrange from 1 =strongly disagree to 5 = strongly agree). In addition, demographic data were collected.

\section{Conducting the survey}

In total, 1417 survey questionnaires were posted to all primary care physicians at three different time points between 2012 and 2015 in both public (polyclinic) and private healthcare sectors ('polyclinic' in the Singapore clinical setting refers to having multiple primary care clinical consultation rooms under one roof). The distinction between public and private sectors was made as providers in the private sector might have a financial incentive to prescribe and dispense antibiotics. Public providers consist of practitioners working in the authors' institution's healthcare cluster. The healthcare cluster belongs to National Healthcare Group, Singapore. Tan Tock Seng Hospital and the polyclinics (public) included in this study are in this healthcare cluster. This is one of two such clusters operating polyclinics scattered across Singapore. The postal addresses of all the private providers were obtained from the Singapore Medical Council database. The anonymous responses were returned using the prepaid envelopes provided. The questionnaire did not contain any identifiers and could not be traced to the participating GP. Individuals who participated were asked not to respond if they received the same survey again.

\section{Statistical analysis}

In order to determine the latent factors influencing antibiotic prescribing by primary care physicians, exploratory factor analysis (EFA) was performed. Factor extraction was done using principal component factoring, and varimax rotation was used to preserve the independence of the factors. The number of factors was decided by inspecting the scree plot, eigenvalues, and the cumulative variance explained. The Kaiser-Meyer-Olkin (KMO) test was performed to check for overall sampling adequacy and Cronbach's $\alpha$ was used to measure the internal consistency of each factor. Logistic regression was performed to identify independent factors associated with low prescribing, adjusted for practice type. Low prescribing was defined as the prescribing of antibiotics by GPs to fewer than $20 \%$ of their patients with AURI, as only $20 \%$ of AURI are caused by bacteria.

All analyses were done using STATA (version 13) and R 3.0.2 at a 5\% significance level.

\section{RESULTS}

The authors received 427 responses (Table 1), of which 351 (82.2\%) were from GPs working in a private practice and the rest were from GPs working in the public sector (polyclinic). The distribution of GPs was similar to that reported in the Singapore Ministry of Health's primary care survey. ${ }^{22}$ Among the survey participants, 148 (34.7\%) held a postgraduate qualification in family medicine. Among those in private practice, two $(0.57 \%)$ had completed their primary medical degree within the previous 5 years, $16(4.56 \%)$ in the previous 6-15years, and $333(94.9 \%)>15$ years previously In the public sector, the numbers were $20(26.3 \%)$, 28 (36.8\%), and 28 (36.8\%) respectively.

Selected KAP responses are summarised in Table 2. Two hundred and five of 351 $(58.4 \%)$ of GPs in the private versus 55 of $76(72.4 \%)$ of those in the public sector recognised that $>80 \%$ of acute respiratory 
Table 1. Demographics of responders

\begin{tabular}{|c|c|c|c|c|c|c|}
\hline & $\begin{array}{l}\text { Private sector } \\
\qquad(n=351)\end{array}$ & $\begin{array}{c}\text { Public sector } \\
\text { (polyclinic) }(n=76)\end{array}$ & $P$-value & $\begin{array}{l}\text { Postgraduate } \\
\text { family medicine } \\
\text { qualifications } \\
\text { (n=148) }\end{array}$ & $\begin{array}{l}\text { Primary medical } \\
\text { qualification only } \\
\qquad(n=279)\end{array}$ & $P$-value \\
\hline \multicolumn{7}{|l|}{ Place of practice, $n(\%)$} \\
\hline Private (solo) & N/A & N/A & & $44(29.7)$ & $67(24.0)$ & \\
\hline Private (group) & $\mathrm{N} / \mathrm{A}$ & $\mathrm{N} / \mathrm{A}$ & & $61(41.2)$ & $179(64.2)$ & \\
\hline Polyclinic & $\mathrm{N} / \mathrm{A}$ & $\mathrm{N} / \mathrm{A}$ & & $43(29.1)$ & 33 (11.8) & $<0.01$ \\
\hline \multicolumn{7}{|c|}{ Number of years from medical school graduation $n(\%)$} \\
\hline$\leq 5$ years & $2(9.1)$ & 20 (90.9) & & 32 (72.7) & 12 (27.3) & \\
\hline 6 to 15 years & $16(36.4)$ & $28(63.6)$ & & $2(9.1)$ & 20 (90.9) & \\
\hline$>15$ years & 333 (92.2) & 28 (7.8) & $<0.01$ & $114(31.6)$ & $247(68.4)$ & $<0.01$ \\
\hline \multicolumn{7}{|l|}{ Highest medical qualification, $n[\%]$} \\
\hline Postgraduate family medicine qualifications & $105(29.9)$ & $43(56.6)$ & $<0.01$ & $\mathrm{~N} / \mathrm{A}$ & N/A & $\mathrm{N} / \mathrm{A}$ \\
\hline Primary medical qualification only & Reference & & & N/A & N/A & N/A \\
\hline
\end{tabular}

infections were caused by viruses $(P=0.02)$.

Regarding clinical indications for giving antibiotics, 377/427 (88.3\%) of responders

thought antibiotics were indicated in acute otitis media, 334 (78.2\%) for acute sinusitis, and 390 (91.3\%) for tonsillitis. About half (228 of $427,53.4 \%$ ) thought that antibiotics were indicated in tracheobronchitis, 103

Table 2. Knowledge, attitude, and practices responses

\begin{tabular}{|c|c|c|c|}
\hline & $\begin{array}{l}\text { GPs from private } \\
\text { practice }(n=351)\end{array}$ & $\begin{array}{l}\text { GPs from } \\
\text { polyclinic }(n=76)\end{array}$ & $P$-value \\
\hline \multicolumn{4}{|l|}{ What percentage of AURI are caused by viruses? $n(\%)$} \\
\hline$<20 \%$ & $14(5.0)$ & $0(0)$ & \\
\hline $20-39 \%$ & $21(6.0)$ & 1 (1.3) & \\
\hline $40-59 \%$ & 107 (30.5) & $18(23.7)$ & \\
\hline $60-79 \%$ & $4(1.1)$ & $2(2.6)$ & \\
\hline$>80 \%$ & $205(58.4)$ & $55(72.4)$ & 0.03 \\
\hline $\begin{array}{l}\text { There is a scoring system to assess the likelihood } \\
\text { of streptococcal infection in pharyngitis/tonsillitis } \\
\text { (modified Centor score), } n(\%)\end{array}$ & $163(46.4)$ & $60(78.9)$ & $<0.01$ \\
\hline $\begin{array}{l}\text { Purulence of nasal discharge/sputum (yellow/green) } \\
\text { indicates increased likelihood of bacterial infection, } n \text { (\%) }\end{array}$ & $197(56.1)$ & 20 (26.3) & $<0.01$ \\
\hline \multicolumn{4}{|l|}{$\begin{array}{l}\text { I think empirical antibiotics are indicated in the } \\
\text { following acute respiratory infections, } n(\%) \text { : }\end{array}$} \\
\hline Acute otitis media & 315 (89.7) & $62(81.6)$ & 0.05 \\
\hline Rhinitis & $12(3.4)$ & $1(1.3)$ & 0.48 \\
\hline Acute sinusitis & $281(80.1)$ & $53(69.7)$ & 0.07 \\
\hline Laryngitis/pharyngitis & $92(26.2)$ & $11(14.5)$ & 0.04 \\
\hline Tonsillitis & $332(94.6)$ & 58 (76.3) & $<0.01$ \\
\hline Tracheobronchitis & $199(56.7)$ & 29 (38.2) & $<0.01$ \\
\hline \multicolumn{4}{|l|}{$\begin{array}{l}\text { What is the proportion of patients with AURI to } \\
\text { whom you prescribe antibiotics? } n(\%)\end{array}$} \\
\hline Low prescriber $(<20 \%)$ & $139(39.6)$ & 61 (80.3) & $<0.01$ \\
\hline \multicolumn{4}{|l|}{$\begin{array}{l}\text { What is the most serious problem you foresee in } \\
\text { overprescription of antibiotics? } n(\%)\end{array}$} \\
\hline Drug-drug interaction & $0(0)$ & $1(1.3)$ & \\
\hline Increased antibiotic resistance & 319 (90.9) & $71(93.4)$ & \\
\hline Increased costs & $2(0.6)$ & 1 (1.3) & \\
\hline Possible side effects/allergies/adverse events & $25(7.1)$ & $3(3.9)$ & \\
\hline Other & $5(1.4)$ & $0(0)$ & 0.18 \\
\hline
\end{tabular}




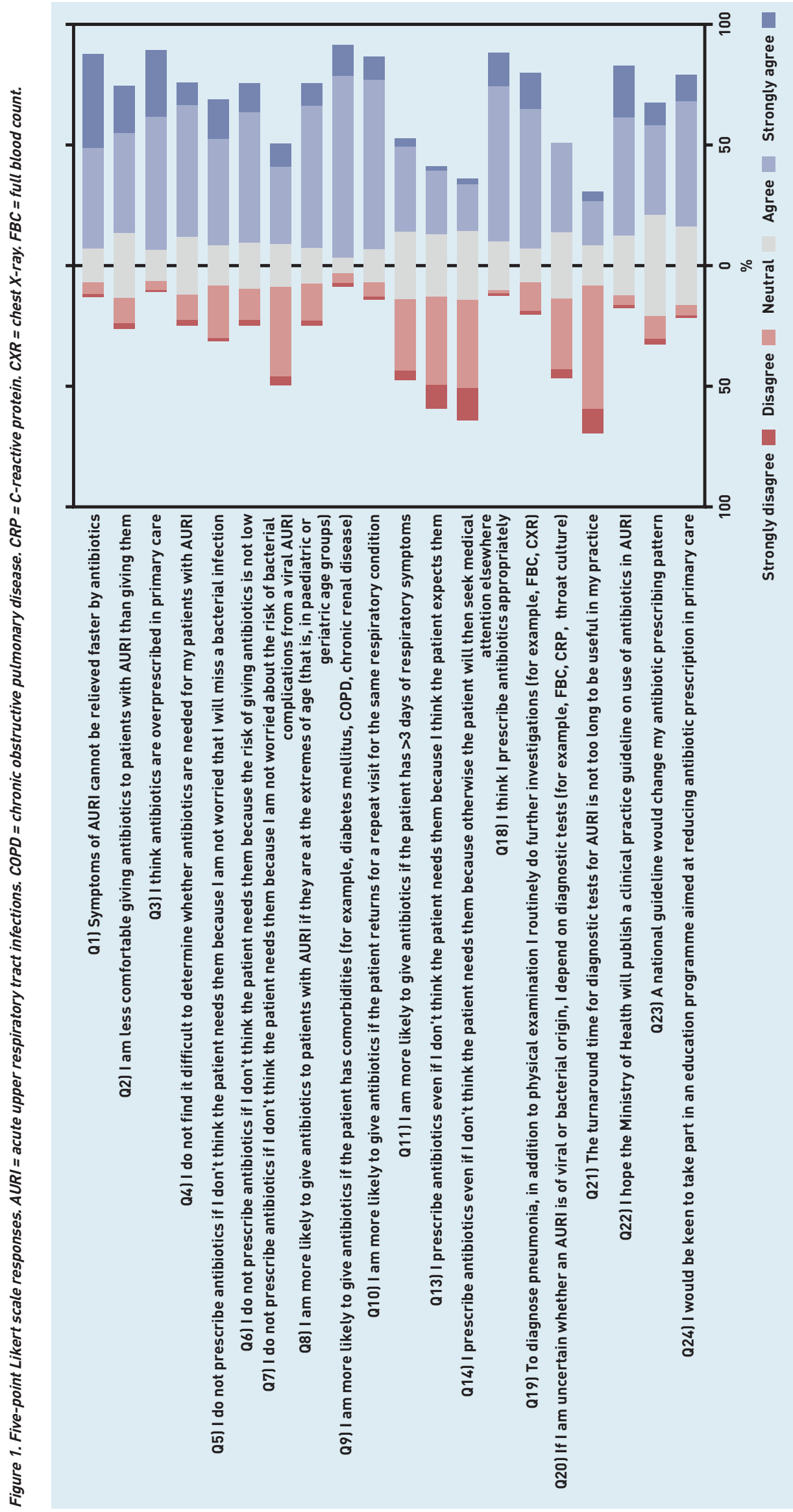

(24.1\%) for laryngitis/pharyngitis, and 13 (3.04\%) for rhinitis.

Among GPs from the private sector, 139/351 (39.6\%) deemed themselves to have a low antibiotic prescribing practice, compared with $61 / 76(80.3 \%)$ of GPs in the public sector polyclinics $(P<0.01)$. Low prescribers were more likely to have obtained their primary medical qualification in Singapore $(P<0.01)$, but did not necessarily have a postgraduate qualification in family medicine $(P=0.45)$. GPs felt that the most serious problems they foresaw in overprescribing antibiotics were:

- the development of antibiotic resistance $(390 ; 91.3 \%)$;

- possible adverse reactions (28; 6.6\%);

- increased costs (3; 0.7\%); and

- drug-drug interactions $(1 ; 0.2 \%)$.

The Likert scale responses are presented in Figures 1 and 2. The majority of GPs (353/427; 82.7\%) thought that antibiotics were overprescribed in the primary care setting (Q3) but most (333/427; 78.0\%) also thought that they prescribed antibiotics appropriately (Q18). Not surprisingly, GPs were more likely to prescribe antibiotics to patients who were at the extremes of age (290/427; 67.9\%) (Q8), had comorbidities (376/427; 88\%) (Q9), and returned for repeat visits for the same respiratory condition (339/427; 79.4\%) (Q10). Only $38.4 \%$ thought that they were more likely to prescribe antibiotics if the patient had $>3$ days of respiratory symptoms (Q11).

The majority $(70.5 \%)$ hoped that the Ministry of Health would publish clinical practice guidelines on antibiotic use in AURI (Q22) although only half (46.3\%) felt that the national guidelines would change their prescribing practices (Q23). Encouragingly, $62.5 \%$ would be keen to take part in an education programme aimed at reducing antibiotic prescribing in primary care (Q24). Based on the number of factors with eigenvalue $>1$ in the scree plot, the authors extracted six factors from the factor analysis for inclusion in the multivariable model (Appendix 2). The six-factor model accounting for $57.5 \%$ of the total variance (KMO test $=0.82$ ) was deemed most suitable. The latent factors are: Factor $1-$ medical knowledge and clinical competency (seven items; loadings ranged from 0.36 to $0.70 ; \alpha=0.74$ ); Factor 2 - conservative practice (giving antibiotics to be on the safe side') (four items; loadings ranged from 0.51 to $0.77 ; \alpha=0.66$ ); Factor 3 - GPs' perceived patient expectations (three items: loadings ranged from 0.62 to $0.73 ; \alpha=0.61$ ); 


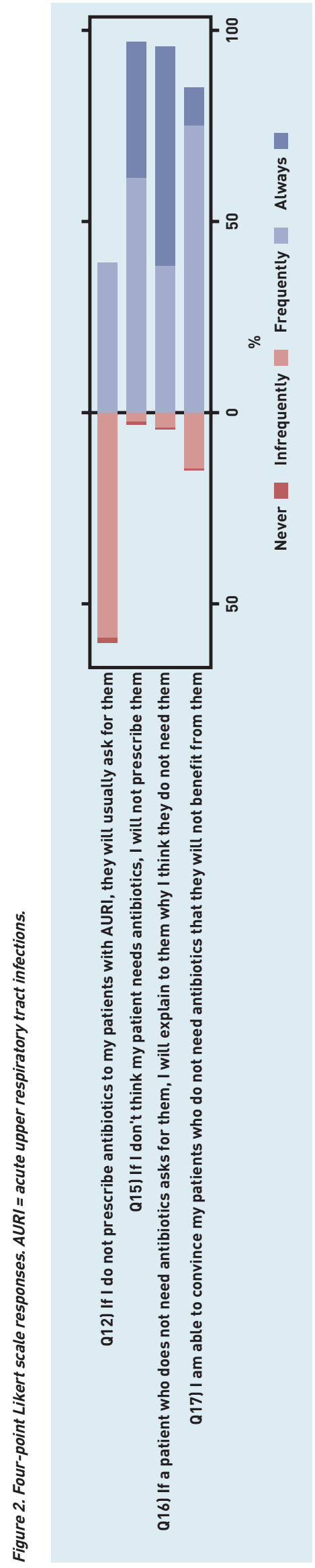

Factor 4 - good clinical practice lfour items; loadings ranged from 0.58 to $0.61 ; \alpha=0.64$ ); Factor 5 - availability of diagnostic tests (three items; loadings ranged from 0.56 to $0.82 ; \alpha=0.62$ ); Factor 6 - desire to improve clinical practice (three items: loadings ranged from 0.70 to $0.83 ; \alpha=0.73$ ) (Table 3). Conservative or prudent practice (giving antibiotics to be on the safe side') was moderately correlated with perceived patient expectations $(r=0.42)$.

On multivariable analysis, medical knowledge and clinical competency $10 \mathrm{R}$ $3.2[95 \% \mathrm{Cl}=2.4$ to 4.3$]$ ), good clinical practice (OR $2.7[95 \% \mathrm{Cl}=2.0$ to 3.6$]$ ), availability of diagnostics IOR 1.4 [95\% $\mathrm{Cl}=1.1$ to 1.8$]$ ), and the desire to improve clinical practice $\operatorname{lOR} 1.5[95 \% \mathrm{Cl}=1.2$ to 1.9]) were significantly associated with low prescribing, after adjusting for the practice type (Table 4). Notably, clinical competency and good clinical practice were most strongly associated with low prescribing. Conservative practice (prescribing antibiotics to be on the safe side') was significantly less likely to be associated with low prescribing (OR: $0.7[95 \% \mathrm{Cl}=0.5$ to 0.9$]$ ).

\section{DISCUSSION}

\section{Summary}

In order to reduce antibiotic prescribing among GPs, it is vital to understand the 'local' beliefs and practices, that is, the cultural and socioeconomic environment, before implementing any interventions. This study has identified physicians' medical knowledge and clinical competency, good clinical practice, availability of diagnostic tests, and desire to improve clinical practice as significant factors associated with low antibiotic prescribing. Being conservative and giving antibiotics to be on the safe side' is also significantly less likely to be associated with low antibiotic prescribing.

\section{Strengths and limitations}

The authors acknowledge that this study could have been limited by bias due to non-participation. However, the profile of GPs who participated in the study was representative of the GP population in Singapore and hence any potential selection bias is likely to be minimal. In addition, although the study's findings were selfreported, the protection of the identity of study participants in the study processes ensured that social desirability bias was very unlikely to have occurred and that the answers provided by the GPs were likely to be authentic. The fact that GPs were not compensated for their time and were not incentivised to participate in the study lends credibility to the findings, as the GPs would have returned the survey questionnaire purely out of their desire to improve clinical practice and patient care.

\section{Comparison with existing literature}

Half $(47.8 \%)$ of GPs were unaware of a scoring system to assess the likelihood of streptococcal throat infection and half (50.8\%) thought that a purulent nasal discharge was indicative of a bacterial infection. In addition, a large proportion (up to $91.3 \%$ ) of GPs thought that empirical antibiotics were indicated for AURI. This analysis showed that medical knowledge and clinical competency (Factor 1) was the most significant factor associated with low prescribing (aOR 3.2, 95\% Cl=2.4 to 4.3). As was similarly observed in the Netherlands, the knowledge gap among GPs on the effects of antibiotics on AURI could lead to high rates of antibiotic prescribing in the community. ${ }^{23}$ An education programme for providers in the UK has shown effectiveness in reducing antibiotic prescribing in primary care $^{24}$ and a similar programme may be adopted in Singapore. Two-thirds (62.5\%) of the GPs in the current study have expressed interest in participating in educational programmes aimed at reducing antibiotic prescribing in primary care.

GPs have been observed to prescribe antibiotics more readily if their patients are at the extremes of age, have significant comorbidities, or have a longer duration of symptoms of AURI, just 'to be on the safe side.., 25 This is probably related to fear of complications in these vulnerable groups. ${ }^{16}$ Although antibiotics were not justified for the prevention of serious complications for AURI, ${ }^{26}$ the current analysis showed that such conservative practice (Factor 2) played a significant role in antibiotic prescribing. Such an approach is significantly less likely to be associated with low prescribing laOR 0.7 [95\% Cl $=0.5$ to 0.9]].

Good clinical practice (Factor 4) was strongly associated with low prescribing laOR $2.7[95 \% \mathrm{Cl}=2.0$ to 3.6$]$ ). Physicians who took the time to explain and convince their patients that antibiotics were not necessary tended to be low prescribers. Patient volume might be a contributory factor, with busier physicians being more liberal in prescribing antibiotics to hasten the consultation process. ${ }^{9.25}$ Interventions should be designed to educate the GPs that antibiotics are not 'quick fix' solutions to speed up consultations, and to simplify the decision-making process. ${ }^{16}$

As discussed earlier, the fear of 


\section{Table 3. The latent factors of antibiotic prescribing}

\begin{tabular}{|c|c|c|c|c|c|}
\hline \multirow[b]{2}{*}{ No. } & \multirow[b]{2}{*}{$\begin{array}{l}\text { Factor } \\
\text { characteristics }\end{array}$} & \multirow[b]{2}{*}{ Survey questions included in the factor loading } & \multicolumn{2}{|c|}{ Factor scores, mean (SD) } & \multirow[b]{2}{*}{$\alpha$} \\
\hline & & & $\begin{array}{c}\text { High } \\
\text { prescribing }\end{array}$ & $\begin{array}{c}\text { Low } \\
\text { prescribing }\end{array}$ & \\
\hline 1 & $\begin{array}{l}\text { Medical knowledge } \\
\text { and clinical } \\
\text { competency }\end{array}$ & $\begin{array}{l}\text { Q1) Symptoms of AURI cannot be relieved faster by antibiotics } \\
\text { Q2) I am less comfortable giving antibiotics to patients with AURI than giving them } \\
\text { Q3) I think antibiotics are overprescribed in primary care } \\
\text { Q4 I do not find it difficult to determine whether antibiotics are needed for my patients with AU } \\
\text { Q5) I do not prescribe antibiotics if I don't think the patient needs them because I am not worrie } \\
\text { that I will miss a bacterial infection } \\
\text { Q6) I do not prescribe antibiotics if I don't think the patient needs them because the risk of givin } \\
\text { antibiotics is not low (for example, an allergic reaction) } \\
\text { Q7) I do not prescribe antibiotics if I don't think the patient needs them because I am not worrie } \\
\text { about the risk of bacterial complications from a viral AURI }\end{array}$ & $\begin{array}{l}-0.36(0.06) \\
\text { JRI } \\
\text { ied } \\
\text { ing }\end{array}$ & $0.41(0.06)$ & 0.74 \\
\hline 2 & $\begin{array}{l}\text { Conservative practice } \\
\text { (giving antibiotics } \\
\text { 'to be on the safe side') }\end{array}$ & $\begin{array}{l}\text { Q8) I am more likely to give antibiotics to patients with AURI if they are at the extremes } \\
\text { of age (that is, in paediatric or geriatric age groups) } \\
\text { Q9) I am more likely to give antibiotics if the patient has comorbidities (for example, diabetes } \\
\text { mellitus, COPD, chronic renal disease) } \\
\text { Q10) I am more likely to give antibiotics if the patient returns for a repeat visit for the same } \\
\text { respiratory condition } \\
\text { Q11) I am more likely to give antibiotics if the patient has }>3 \text { days of respiratory symptoms }\end{array}$ & $0.12(0.06)$ & $-0.13(0.08)$ & 0.66 \\
\hline 3 & $\begin{array}{l}\text { GPs' perceived } \\
\text { patient expectations }\end{array}$ & $\begin{array}{l}\text { Q12) If I do not prescribe antibiotics to my patients with AURI, they will usually ask for them } \\
\text { Q13) I prescribe antibiotics even if I don't think the patient needs them because I think } \\
\text { the patient expects them } \\
\text { Q14) I prescribe antibiotics even if I don't think the patient needs them because otherwise } \\
\text { the patient will then seek medical attention elsewhere }\end{array}$ & $-0.06(0.07)$ & $0.07(0.07)$ & 0.61 \\
\hline 4 & Good clinical practice & $\begin{array}{l}\text { Q15) If I don't think my patient needs antibiotics, I will not prescribe them } \\
\text { Q16) If a patient who does not need antibiotics asks for them, I will explain to them why } \\
\text { I think they do not need them } \\
\text { Q17) I am able to convince my patients who do not need antibiotics that they will } \\
\text { not benefit from them } \\
\text { Q18) I think I prescribe antibiotics appropriately }\end{array}$ & $-0.31(0.07)$ & $0.35(0.07)$ & 0.64 \\
\hline 5 & $\begin{array}{l}\text { Availability of } \\
\text { diagnostic tests }\end{array}$ & $\begin{array}{l}\text { Q19) To diagnose pneumonia, in addition to physical examination I routinely do further } \\
\text { investigations (for example, FBC, CXR) } \\
\text { Q20) If I am uncertain whether an AURI is of viral or bacterial origin, I depend on diagnostic } \\
\text { tests (for example, FBC, CRP, throat culture). } \\
\text { Q21 The turnaround time for diagnostic tests for AURI infections is not too long to be } \\
\text { useful in my practice }\end{array}$ & $-0.15(0.06)$ & $0.17(0.08)$ & 0.62 \\
\hline 6 & $\begin{array}{l}\text { Desire to improve } \\
\text { clinical practice }\end{array}$ & $\begin{array}{l}\text { Q22) I hope the Ministry of Health will publish a clinical practice guideline on use of } \\
\text { antibiotics in AURI } \\
\text { Q23) A national guideline would change my antibiotic prescribing pattern } \\
\text { Q24) I would be keen to take part in an education programme aimed at reducing antibiotic } \\
\text { prescription in primary care }\end{array}$ & $-0.16(0.07)$ & $0.18(0.07)$ & 0.73 \\
\hline
\end{tabular}

$A U R I=$ acute upper respiratory tract infections. $C O P D=$ chronic obstructive pulmonary disease. $C R P=C$-reactive protein. $C X R=$ chest $X$-ray. FBC $=$ full blood count.

Table 4. Effects sizes of the six latent factors on low prescribing

\begin{tabular}{|c|c|c|c|c|}
\hline & $\begin{array}{c}\text { Univariate OR } \\
\text { (95\% CI) }\end{array}$ & $P$-value & $\begin{array}{l}\text { Multivariable aOR } \\
\qquad(95 \% \mathrm{Cl})^{\mathrm{a}}\end{array}$ & $P$-value \\
\hline Factor 1: Medical knowledge and clinical competency & 2.5 (2.0 to 3.3) & $<0.01$ & 3.2 (2.4 to 4.3$)$ & $<0.01$ \\
\hline Factor 2: Conservative practice (giving antibiotics 'to be on the safe side') & 0.8 (0.6 to 0.9$)$ & 0.01 & 0.7 (0.5 to 0.9$)$ & $<0.01$ \\
\hline Factor 3: GPs' perceived patient expectations & $1.1(0.9$ to 1.4$)$ & 0.21 & - & - \\
\hline Factor 4: Good clinical practice & 2.1 (1.7 to 2.7$)$ & $<0.01$ & $2.7(2.0$ to 3.6$)$ & $<0.01$ \\
\hline Factor 5: Availability of diagnostic tests & $1.4(1.1$ to 1.7$)$ & $<0.01$ & $1.4(1.1$ to 1.8$)$ & $<0.01$ \\
\hline Factor 6: Desire to improve clinical practice & $1.4(1.2$ to 1.7$)$ & $<0.01$ & $1.5(1.2$ to 1.9$)$ & $<0.01$ \\
\hline
\end{tabular}

aOR $=$ adjusted odds ratio. ${ }^{\circ}$ Adjusted for practice type. 
misdiagnosis of viral AURI or the development of complications from it contribute to increased antibiotic prescribing by GPs. Not surprisingly, the availability of diagnostic tests (Factor 5) was observed to influence prescribing decisions in this study's multivariate analysis laOR 1.4 [95\% Cl=1.1 to 1.8$]$ ] and $281 / 427(65.8 \%$ ] of the participants expressed a willingness to use a point-of-care (POC) test to guide their antibiotic prescribing. A systematic review by Aabenhus and colleagues showed that using POC C-reactive protein testing reduced antibiotic use for AURI in primary care settings without affecting patient-reported outcomes, including recovery from and duration of illness. ${ }^{27}$ The use of another inflammatory marker, procalcitonin, has been investigated in a few primary care studies. The studies showed a reduction in the prescribing of antibiotics when procalcitonin-guided therapy was used, without significant effects on safety. ${ }^{28,29}$ However, the use of procalcitonin in the primary care setting is limited due to a lack of feasible POC tests. Further clinical implementation studies on POC C-reactive protein tests should be conducted in Singapore to assess for the acceptability of the tests in clinical practice and the effectiveness in improving antibiotic prescribing practices.

It was found that GPs desire to improve on prescribing practices (Factor 6) was associated with low antibiotic prescribing laOR $1.5[95 \% \mathrm{Cl}=1.2$ to 1.9$]$ ] Most GPs were keen to take part in education programmes aimed at reducing antibiotic use. The majority (301 of $427 ; 70.5 \%$ ) would like to have national clinical practice guidelines on the use of antibiotics in AURI. However, only about half (46.3\%) expressed that such guidelines would change their prescribing practices. Further qualitative studies are required to understand the perception of GPs on the usefulness of guidelines and the preferred form of the guidelines to support their antibiotic prescribing practices.

GPs' perceived patient expectation of receiving antibiotics (Factor 3 ) was often cited as a reason for antibiotic prescribing by primary care providers. In the current study, however, the perceived patient expectation was not a significant factor associated with antibiotic prescribing. This could be due to a lower level of health literacy in people in Singapore, who were less likely to discuss clinical management decisions with their healthcare providers.
In previous studies in Western and Asian populations, patients have been observed to have a variable knowledge about the role of antibiotics in the common cold and cough, ${ }^{30,31}$ and those with a suboptimal knowledge of antibiotics tended to request antibiotics from their GPs. Patients who requested antibiotics were more likely to have them prescribed. ${ }^{30,32}$ Perceived patient expectation of receiving antibiotics causes inappropriate prescribing as GPs attempt to pre-empt their patients' wishes. Unfortunately, these perceptions were often inaccurate. ${ }^{33}$ In a study conducted in emergency departments, physicians were more likely to prescribe antibiotics to patients they believed expected to receive them but they only correctly identified one in four such patients. ${ }^{34}$ Another reason why this study did not observe an association between perceived patient expectation and antibiotic prescribing may be that the more patriarchal doctor-patient relationships in Singapore result in fewer patient requests to doctors. In a study of doctor-patient relationships in Singapore, doctors believed that many of their patients were incapable of rational decision making, reflecting the elitism of the educated class, which is held in high regard in Asian societies. ${ }^{35}$ In a study among local medical students, there was a lower propensity for Singapore students to view the doctor-patient relationship as a partnership compared with students in the US. ${ }^{36}$ With an increasingly educated and assertive population in Singapore, GPs might progressively tailor their prescribing practices to satisfy their patients. A recent study in the UK reported that high antibiotic prescribing volume was a significant positive predictor of all 'doctor satisfaction' and 'practice satisfaction' scores, and was the strongest predictor of overall satisfaction out of 13 prescribing variables. ${ }^{37}$

\section{Implications for research and practice}

To the authors' knowledge, this is the first KAP survey on antibiotic prescribing for AURI in primary care in Singapore. Interventions addressing these factors, including a tailored educational programme and national antibiotic guidelines, could improve antibiotic prescribing practices and reduce unnecessary antibiotic use in primary care settings. Future research directed at patient factors influencing antibiotic use will help in designing these educational programmes in the bid to reduce antibiotic use in the community.

\section{Discuss this article}

Contribute and read comments about this article: bjgp.org/letters 


\section{REFERENCES}

1. Kenealy T, Arroll B. Antibiotics for the common cold and acute purulent rhinitis. Cochrane Database Syst Rev 2013; (6): CD000247. DOI: 10.1002/14651858. CD000247.pub3.

2. Smith SM, Fahey T, Smucny J, Becker LA. Antibiotics for acute bronchitis. Cochrane Database Syst Rev 2014; (3): CD000245. D0I: 10.1002/14651858. CD000245.pub3.

3. Office-related antibiotic prescribing for persons aged $\leq 14$ years - United States, 1993-1994 to 2007-2008. MMWR Morb Mortal Wkly 2011; 60(34): 1153-1156.

4. Gonzales R, Steiner JF, Sande MA. Antibiotic prescribing for adults with colds, upper respiratory tract infections, and bronchitis by ambulatory care physicians. JAMA 1997; 278(11): 901-904.

5. Gonzales R, Malone DC, Maselli JH, Sande MA. Excessive antibiotic use for acute respiratory infections in the United States. Clin Infect Dis 2001; 33(6): 757-762.

6. Public Health England. English surveillance programme for antimicrobial utilisation and resistance (ESPAUR) 2010 to 2014. Report 2015. https://www. gov.uk/government/uploads/system/uploads/attachment_data/file/477962/ ESPAUR_Report_2015.pdf (accessed 19 Dec 2016).

7. Neu HC. The crisis in antibiotic resistance. Science 1992; 257(5073): 1064-1073.

8. Vasoo S, Singh K, Hsu LY, et al. Increasing antibiotic resistance in Streptococcus pneumoniae colonizing children attending day-care centres in Singapore. Respirology 2011; 16(8): 1241-1248.

9. Hofmann J, Cetron MS, Farley MM, et al. The prevalence of drug-resistant Streptococcus pneumoniae in Atlanta. N Engl J Med 1995; 333(8): 481-486.

10. Costelloe C, Metcalfe C, Lovering A, et al. Effect of antibiotic prescribing in primary care on antimicrobial resistance in individual patients: systematic review and meta-analysis. BMJ 2010; 340: c2096.

11. Emmanuel SC, Phua HP, Cheong PY. 2001 survey on primary medical care in Singapore. Singapore Med J 2004; 45(5): 199-213.

12. Lim KH, Yap KB. The prescribing pattern of outpatient polyclinic doctors. Singapore Med J 1999; 40(6): 416-419.

13. Kumar S, Little $P$, Britten N. Why do general practitioners prescribe antibiotics for sore throat? Grounded theory interview study. BMJ 2003; 326(7381): 138.

14. Altiner A, Brockmann S, Sielk M, et al. Reducing antibiotic prescriptions for acute cough by motivating GPs to change their attitudes to communication and empowering patients: a cluster randomized intervention study. J Antimicrob Chemother 2007; 60(3): 638-644.

15. Vazquez-Lago JM, Lopez-Vazquez P, López-Durán A et al. Attitudes of primary care physicians to the prescribing of antibiotics and antimicrobial resistance: $a$ qualitative study from Spain. Fam Pract 2012; 29(3): 352-360.

16. Wood F, Phillips C, Brookes-Howell L, et al. Primary care clinicians' perceptions of antibiotic resistance: a multi-country qualitative interview study. J Antimicrob Chemother 2013; 68(1): 237-243.

17. Cockburn J, Pit S. Prescribing behaviour in clinical practice: patients expectations and doctors' perceptions of patients' expectations: a questionnaire study. BMJ 1997; 315(7107): 520-523

18. Arroll B, Goodyear-Smith F, Thomas DR, Kerse N. Delayed antibiotic prescriptions: what are the experiences and attitudes of physicians and patients? J Fam Pract 2002; 51(11): 954-959.

19. Steinman MA, Landefeld CS, Gonzales R. Predictors of broad-spectrum antibiotic prescribing for acute respiratory tract infections in adult primary care. JAMA 2003; 289(6): 719-725.
20. Teixeira Rodrigues A, Roque F, Falcão A, et al. Understanding physician antibiotic prescribing behaviour: a systematic review of qualitative studies. Int $J$ Antimicrob Agents 2013; 41(3): 203-212.

21. World Health Organization. Global action plan on antimicrobial resistance. 2015 http://www.who.int/antimicrobial-resistance/publications/global-action-plan/en/ laccessed 19 Dec 2016).

22. Sng QS. Primary care survey 2010: profile of primary care patients. Singapore: Ministry of Health, 2010.

23. Akkerman A, Marijke K, Johannes VDW, Theo V. Prescribing antibiotics for respiratory tract infections by GPs: management and prescriber characteristics. Br J Gen Pract 2005; 55(511): 114-118.

24. Butler C, Simpson S, Dunstan F, et al. Effectiveness of multifaceted educational programme to reduce antibiotic dispensing in primary care: practice based randomised controlled trial. BMJ 2012; 344: d8173.

25. Kotwani A, Wattal C, Katewa S, et al. Factors influencing primary care physicians to prescribe antibiotics in Delhi India. Fam Pract 2010; 27(6): 684690.

26. Petersen I, Johnson AM, Islam A, et al. Protective effect of antibiotics against serious complications of common respiratory tract infections: retrospective cohort study with the UK General Practice Research Database. BMJ 2007; 335: 982.

27. Aabenhus R, Jensen JUS, Jørgensen KJ, et al. Biomarkers as point-of-care tests to guide prescription of antibiotics in patients with acute respiratory infections in primary care. Cochrane Database Syst Rev 2014; (11): CD010130.

28. Briel M, Schuetz P, Mueller B, et al. Procalcitonin-guided antibiotic use vs a standard approach for acute respiratory tract infections in primary care. Arch Intern Med 2008; 168(18): 2000-2007; discussion 2007-2008.

29. Burkhardt $\mathrm{O}$, Ewig $\mathrm{S}$, Haagen $\mathrm{U}$, et al. Procalcitonin guidance and reduction of antibiotic use in acute respiratory tract infection. Eur Respir J 2010; 36(3): 601-607.

30. McNulty CA, Nichols T, French DP, et al. Expectations for consultations and antibiotics for respiratory tract infection in primary care: the RTI clinical iceberg. Br J Gen Pract 2013; DOI: 10.3399/bjgp13X669149.

31. Ling Oh A, Hassali MA, Al-Haddad MS, et al. Public knowledge and attitudes towards antibiotic usage: a cross-sectional study among the general public in the state of Penang, Malaysia. J Infect Dev Ctries 2011; 5(5): 338-347.

32. Sung L, Arroll J, Arroll B, et al. Antibiotic use for upper respiratory tract infections before and after a education campaign as reported by general practitioners in New Zealand. N Z Med J 2006; 119(1233): U1956.

33. Altiner A, Knauf A, Moebes J, et al. Acute cough: a qualitative analysis of how GPs manage the consultation when patients explicitly or implicitly expect antibiotic prescriptions. Fam Pract 2004; 21(5): 500-506.

34. Ong S, Nakase J, Moran GJ, et al. Antibiotic use for emergency department patients with upper respiratory infections: prescribing practices, patient expectations, and patient satisfaction. Ann Emerg Med 2007; 50(3): 213-220.

35. Chan D, Goh LG. The doctor-patient relationship: a survey of attitudes and practices of doctors in Singapore. Bioethics 2000; 14(1): 58-76.

36. Lee KH, Seow A, Luo N, Koh D. Attitudes towards the doctor-patient relationship: a prospective study in an Asian medical school. Med Educ 2008: 42(11): 1092-1099

37. Ashworth $M$, White $P$, Jongsma $H$, et al. Antibiotic prescribing and patient satisfaction in primary care in England: cross-sectional analysis of national patient survey data and prescribing data. Br J Gen Pract 2016; DOI: 10.3399/ bjgp15X688105. 


\section{Appendix 1. Knowledge, attitudes, and practices survey and variable types}

\section{Variable list}

Type of variable

Where is your current place of medical practice?

How long ago did you graduate from medical school?

Categorical (3 levels)

Where did you attend medical school?

Binary

What is your highest medical qualification?

Categorical (4 levels)

What percentage of AURI are caused by viruses?

Scale $(1-5)$

What is the proportion of patients with AURI to whom you prescribe antibiotics?

Q1) Symptoms of AURI cannot be relieved faster by antibiotics

Scale (1-5)

Q2) I am less comfortable giving antibiotics to patients with AURI than giving them

Scale (1-5)

Q3) I think antibiotics are overprescribed in primary care

Scale (1-5)

Q4) I do not find it difficult to determine whether antibiotics are needed for my patients with AUR

Scale (1-5)

Q5) I do not prescribe antibiotics if I don't think the patient needs them because I am not worried that I will miss a bacterial infection

Scale $(1-5)$

Q6) I do not prescribe antibiotics if I don't think the patient needs them because the risk of giving antibiotics is not low

Scale $(1-5)$

Q7) I do not prescribe antibiotics if I don't think the patient needs them because I am not worried about the risk of bacteria Scale (1-5) complications from a viral AUR

Q8) I am more likely to give antibiotics to patients with AURI if they are at the extremes of age (that is, in the paediatric or geriatric age groups)

Scale $(1-5)$

Scale $(1-5)$

Q9) I am more likely to give antibiotics if the patient has comorbidities (for example, diabetes mellitus, COPD, chronic renal disease)

Scale $(1-5)$

Q10) I am more likely to give antibiotics if the patient returns for a repeat visit for the same respiratory condition

Q11) I am more likely to give antibiotics if the patient has more than 3 days of respiratory symptoms

Scale (1-5)

Q12) If I do not prescribe antibiotics to my patients with AURI, they will usually ask for them

Scale (1-5)

Q13) I prescribe antibiotics even if I don't think the patient needs them because I think the patient expects it

Scale $(1-4)$

Q14) I prescribe antibiotics even if I don't think the patient needs them because otherwise the patient will then seek medical Scale (1-5) attention elsewhere

Q15) If I don't think my patient needs antibiotics, I will not prescribe them

Scale (1-5)

Scale (1-4)

Q16) If a patient who does not need antibiotics asks for them, I will explain to them why I think they do not need them

Scale (1-4)

Q17) I am able to convince my patients who do not need antibiotics that they will not benefit from them

Q18) I think I prescribe antibiotics appropriately

Q19) To diagnose pneumonia, in addition to physical examination I routinely do further investigations (for example, FBC, CXR)

Q20) If I am uncertain whether an AURI is of viral or bacterial origin, I depend on diagnostic tests (for example, FBC, CRP, throat culture)

Scale (1-5)

Q21) The turnaround time for diagnostic tests for AURI is not too long to be useful in my practice

Scale $(1-5)$

Q22) I hope the Ministry of Health will publish a clinical practice guideline on the use of antibiotics in AURI

Scale (1-5)

Q23) A national guideline would change my antibiotic prescribing pattern

Scale (1-5)

Q24) I would be keen to take part in an education programme aimed at reducing antibiotic prescription in primary care

Scale $(1-5)$

$A U R I=$ acute upper respiratory tract infections. $C O P D=$ chronic obstructive pulmonary disease. $C R P=C$-reactive protein. $C X R=$ chest $X$-ray. $F B C=$ full blood count

Questions were either on a 4-point (1 = never, 2 = infrequently, 3 = frequently, $4=$ always) or a 5-point Likert scale (range from $1=$ strongly disagree to $5=$ strongly agree). 


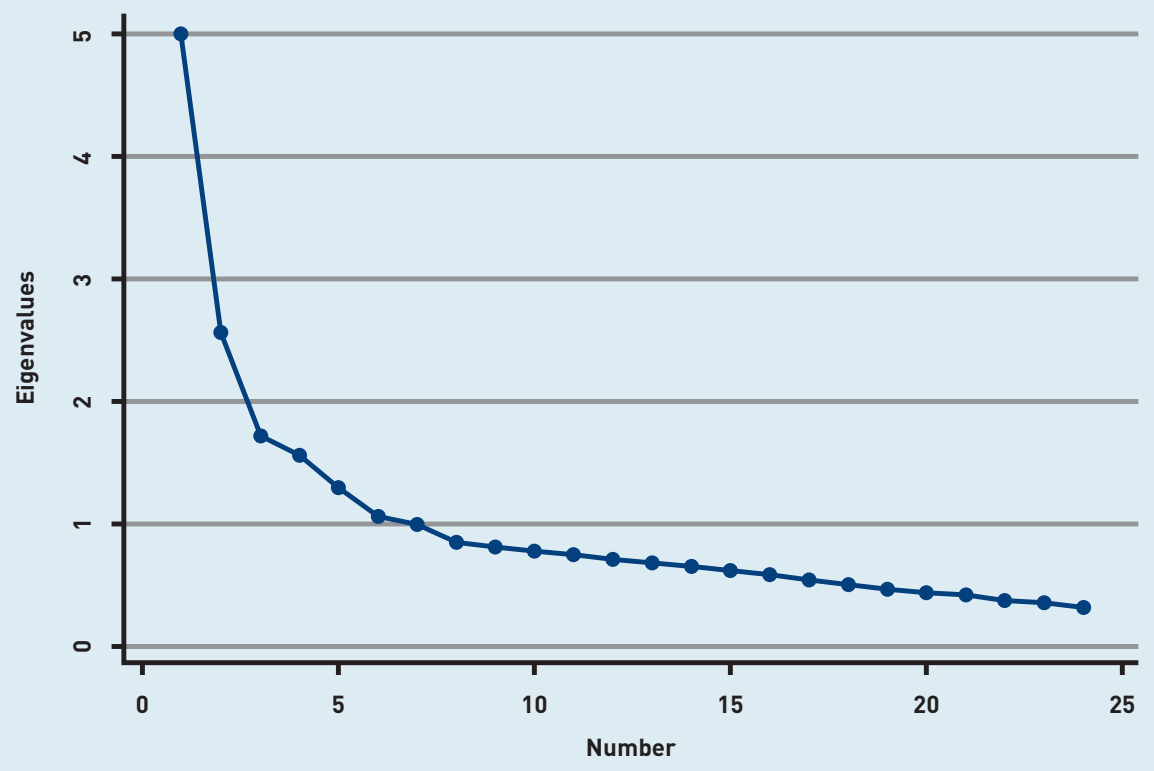

Appendix 2. Scree plot of number of factors and the eigenvalues. Factor $1=$ medical knowledge and clinical competency; Factor 2 = conservative practice; Factor 3 = GPs' perceived patient expectations; Factor 4 = good clinical practice; Factor 5 = availability of diagnostic tests; Factor $6=$ desire to improve clinical practice - this was also moderately correlated with perceived patient expectations ( $\mathrm{r}=0.42)$. 